\title{
Cerebral revascularization for the management of complex intracranial aneurysms: a single-center experience
}

\author{
Eric S. Nussbaum, MD, ${ }^{1}$ Kevin M. Kallmes, MA, ${ }^{2}$ Jeffrey P. Lassig, MD, ${ }^{1}$ James K. Goddard, MD, ${ }^{1}$ \\ Michael T. Madison, MD, ${ }^{1}$ and Leslie A. Nussbaum, MD, PhD'
}

${ }^{1}$ National Brain Aneurysm Center, Department of Neurosurgery, United Hospital, St. Paul, Minnesota; and 2Duke University Law School, Durham, North Carolina

OBJECTIVE Because simple intracranial aneurysms (IAs) are increasingly treated endovascularly, neurovascular surgery has become focused on complex IAs that may require deconstructive aneurysm therapy with concomitant surgical bypass. The authors describe the decision-making process concerning cerebral revascularization and present outcomes that were achieved in a large case series of complex IAs managed with cerebral revascularization and parent artery occlusion.

METHODS The authors retrospectively reviewed the medical records, including neuroimaging studies, operative reports, and follow-up clinic notes, of all patients who were treated at the National Brain Aneurysm Center between July 1997 and June 2015 using cerebral revascularization as part of the management of an IA. They recorded the location, rupture status, and size of each IA, as well as neurological outcome using the modified Rankin Scale (mRS), aneurysm and bypass status at follow-up, and morbidity and mortality.

RESULTS The authors identified 126 patients who underwent revascularization surgery for 126 complex, atheromatous, calcified, or previously coiled aneurysms. Ninety-seven lesions (77.0\%) were unruptured, and $99(78.6 \%)$ were located in the anterior circulation. Aneurysm size was giant $(\geq 25 \mathrm{~mm})$ in 101 patients, large $(10-24 \mathrm{~mm})$ in 9 , and small $(\leq 9 \mathrm{~mm})$ in 16 patients. Eighty-four low-flow bypasses were performed in 83 patients (65.9\%). High-flow bypass was performed in 32 patients $(25.4 \%)$. Eleven patients (8.7\%) underwent in situ or intracranial-intracranial bypasses. Major morbidity (mRS score 4 or 5$)$ occurred in $2(2.4 \%)$ low-flow cases and $3(9.1 \%)$ high-flow cases. Mortality occurred in $2(2.4 \%)$ low-flow cases and 2 (6.1\%) high-flow cases. At the 12-month follow-up, 83 (98.8\%) low-flow and 30 (93.8\%) high-flow bypasses were patent. Seventy-five patients $(90.4 \%)$ undergoing low-flow and $28(84.8 \%)$ high-flow bypasses had an mRS score $\leq 2$. There were no statistically significant differences in patency rates or complications between low- and high-flow bypasses.

CONCLUSIONS When treating challenging and complex IAs, incorporating revascularization strategies into the surgical repertoire may contribute to achieving favorable outcomes. In our series, low-flow bypass combined with isolated proximal or distal parent artery occlusion was associated with a low rate of ischemic complications while providing good longterm aneurysm control, potentially supporting its wider utilization in this setting. The authors suggest that consideration should be given to managing complex IAs at high-volume centers that offer a multidisciplinary team approach and the full spectrum of surgical and endovascular treatment options to optimize patient outcomes.

https://thejns.org/doi/abs/10.3171/2018.4.JNS172752

KEYWORDS complex aneurysms; revascularization; high-flow bypass; low-flow bypass; vascular disorders

$\mathrm{I}$ $\mathrm{N}$ an era when endovascular therapy has produced consistently favorable outcomes for straightforward intracranial aneurysms (IAs), ${ }^{17,33}$ the role of neurovascular surgery in IA treatment has become increasingly focused on aneurysms that are too complex for conventional clip- ping or simple endovascular coiling. ${ }^{10,21,31,32}$ Large, giant, or wide-necked aneurysms, particularly those that are atheromatous, calcified, or previously coiled, remain a significant challenge to microsurgical clipping or endovascular coiling. ${ }^{27}$ Similarly, fusiform aneurysms that incorporate

ABBREVIATIONS $\mathrm{ACA}=$ anterior cerebral artery; $\mathrm{BTO}=$ balloon test occlusion; $\mathrm{ECA}=$ external carotid artery; $\mathrm{IA}=$ intracranial aneurysm; IC = intracranial; ICA = internal carotid artery; $\mathrm{MCA}=$ middle cerebral artery; $\mathrm{mRS}=$ modified Rankin Scale; $\mathrm{OA}=$ occipital artery; $\mathrm{PCA}=$ posterior cerebral artery; $\mathrm{PICA}=$ posterior inferior cerebellar artery; $\mathrm{SAH}=$ subarachnoid hemorrhage; STA = superficial temporal artery.

SUBMITTED October 30, 2017. ACCEPTED April 17, 2018.

INCLUDE WHEN CITING Published online October 26, 2018; DOI: 10.3171/2018.4.JNS172752. 
normal branches and perforators may be difficult to treat. In these cases, rapidly evolving stent technology will likely play an increasing role as a management option in the future. ${ }^{2,27}$ However, there remains a subset of highly challenging cases that may be best treated with specialized microsurgical techniques.

When addressing the most complicated large and giant IAs, treatment options include complex surgical approaches such as deep hypothermic circulatory arrest as well as aneurysmorrhaphy with thrombectomy. ${ }^{4,15,22}$ Alternatively, these challenging lesions can be managed using parent artery occlusion combined with creative forms of cerebral revascularization to maintain adequate blood flow to the distal vascular territory. ${ }^{1-9}$ As the indications for endovascular therapy widen, maintaining highly specialized centers that provide a full range of endovascular and surgical approaches, including cerebral revascularization, is necessary to ensure that complex aneurysms can be addressed adequately. This report details our experience with cerebral revascularization procedures in a large series of complex IAs for which traditional clip reconstruction or endovascular repair were felt to carry unacceptably high risks of major complication. We also present an analysis of our decision-making for choosing low- versus high-flow bypass and compare patency and complication rates between bypass types.

\section{Methods \\ Patient Selection}

We retrospectively reviewed the medical records of all patients with an IA treated by a single surgeon at the National Brain Aneurysm Center from July 1997 to June 2015. Of roughly 2500 patients from the study period whose aneurysms were treated surgically, we retrospectively identified 126 patients (5.0\%) whose complex IAs were treated using revascularization and occlusion of the parent artery. These aneurysms were considered "complex" by our multidisciplinary team when traditional treatment methods, including clipping, coiling, or stenting, were felt to carry unacceptably high treatment risks, exceeding 5\%-10\%. Reasons for the high estimated treatment risk in these cases included large or giant aneurysm size with associated distortion of the normal microsurgical anatomy, fusiform aneurysm nature with incorporation of parent/perforating/efferent vessels into the aneurysm, and/or atheroma/calcification within the aneurysm wall. Complete hospital and outpatient medical records, including neuroimaging studies, operative reports, and follow-up clinic notes, were reviewed in all cases. Each case was preoperatively reviewed by a multidisciplinary neurovascular team comprising a neurovascular surgeon and an interventional neuroradiologist, who decided that a strategy of revascularization and parent artery occlusion would carry the best chance for a favorable outcome. We further based our treatment decision concerning whether to complete a bypass and, if so, whether the bypass should be high or low flow, using the decision matrix and neuroimaging studies as described below.

\section{Preoperative Imaging}

All patients underwent CT scanning and MRA (unless contraindicated due to metallic implant) as well as 4-vessel catheter 3D rotational cerebral angiography. When ICA sacrifice was contemplated, additional cerebral blood flow testing included a balloon test occlusion (BTO) with Xenon-enhanced CT (until 2000) or SPECT perfusion imaging (after 2000). Cerebral blood flow dynamics were assessed based on findings from these neuroimaging studies. In some cases, additional information was obtained regarding the adequacy of collateral and bypass-augmented flow using intraoperative angiographic evaluation.

\section{Preoperative Balloon Test Occlusion}

Preoperative BTO evaluation ${ }^{23}$ was utilized in cases when sacrifice of the internal carotid artery (ICA) was contemplated. In our practice, we have used BTO to stratify patients in terms of stroke risk associated with ICA occlusion. Patients are categorized into 3 groups based on angiographic findings and clinical neurological examination, as outlined in Fig. 1, to help determine treatment recommendations. In general, patients who did not pass clinically were offered high-flow bypass if the ICA was to be sacrificed. Patients who passed both clinically and based on adjunctive imaging findings were offered lowflow bypass if they were younger than 65 years and in good health; otherwise, occlusion without bypass was offered. Those patients who did not undergo bypass were excluded from this study. Patients who passed clinically but did not pass based on imaging criteria underwent high-flow bypass if they were younger than 40 years or low-flow bypass if older than 40 years, in poor health, or when the superficial temporal artery (STA) was particularly large in caliber. This classification system was designed to identify those patients who would maintain adequate blood flow with low-flow bypass alone, which, in our experience, is a shorter and more straightforward procedure and therefore may carry lower morbidity rates than high-flow graft options as long as adequate blood flow is achieved. STA size and patient age were considered important factors when trying to balance the risk of perioperative complications with the need to maintain adequate blood supply to prevent distal ischemia following parent artery occlusion.

\section{Bypass and Occlusion Techniques}

Our techniques for bypass procedures have been described previously, ${ }^{19}$ including differentiation of patients based on bypass type. ${ }^{24}$ When an aneurysm was located on a distal middle cerebral artery (MCA) branch, we used intraoperative angiography to confirm that we were bypassing to the correct territory (a cortical branch arising from the involved artery). During the same operation, once the revascularization procedure had been completed, we proceeded to treat the IAs surgically by sacrificing the parent artery with proximal occlusion, when possible. We have generally avoided aneurysm trapping in order to limit potential ischemia to perforators arising from the trapped segment. When access to the parent artery proximal to the aneurysm was precluded based on anatomical considerations, we utilized a method of distal occlusion that has been described previously. ${ }^{18}$ Delayed endovascu- 


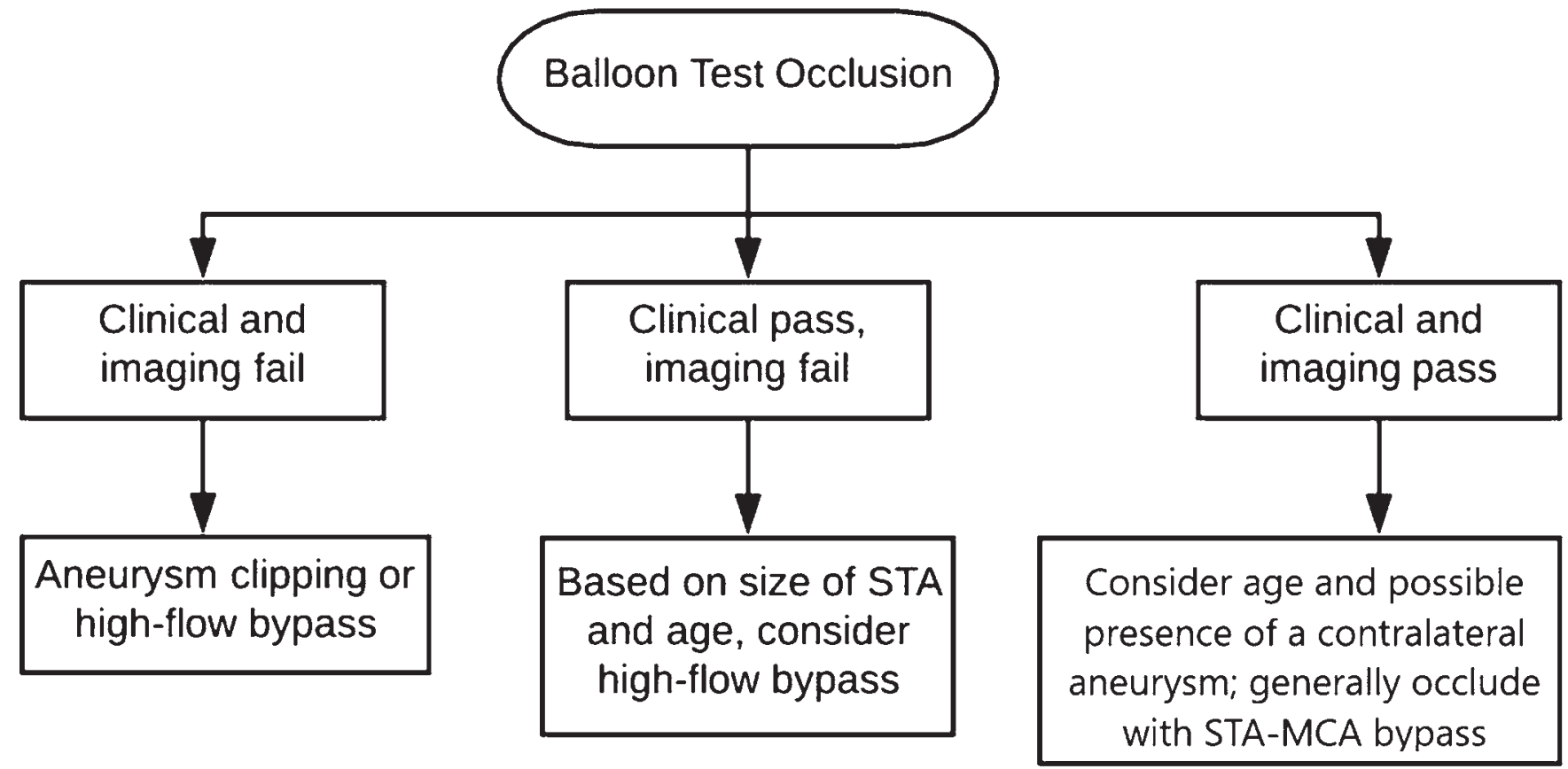

FIG. 1. Revascularization management based on BTO findings. This test stratifies patients based on clinical and angiographic examination into high-flow bypass, low-flow bypass, or occlusion without bypass. A high-flow bypass is used when parent artery sacrifice is necessary and patients failed the BTO either clinically or angiographically, while low-flow bypass is offered to patients who passed the test; the caliber of the STA and patient age are also taken into account. Reprinted with a modification from Nussbaum ES, Mocco J: Cerebral Revascularization: Microsurgical and Endovascular Techniques. Stuttgart: Thieme Medical Publishers, 2011, with permission.

lar parent artery occlusion was utilized in 15 cases, either immediately after surgery during the same general anesthesia session or within the first 72 hours after surgery as a separate procedure. These patients underwent endovascular occlusion of the cervical ICA (6 cases), peripheral MCA branch (5 cases), $\mathrm{M}_{1}$ segment (2 cases), or vertebral artery ( 2 cases). We also performed 5 (4.0\%) short intracranial (IC)-IC grafts from the ICA to the proximal MCA branches or from MCA-MCA, one of which was previously reported, ${ }^{20}$ and $6(4.8 \%)$ posterior inferior cerebellar artery (PICA)-PICA in situ grafts. Since neither of these has been classified as high- or low-flow in previous studies, they were excluded from high- versus low-flow comparisons.

\section{Follow-Up and Outcomes}

We completed follow-up with all surviving patients at a minimum of 12 months after surgery. Neurological outcomes were measured using the modified Rankin Scale (mRS). The mRS scores were determined by reviewing the dictated nursing and physician notes of postoperative follow-up visits. Bypass patency and aneurysm status were observed using angiography, which was performed by an interventional neuroradiologist at the time of follow-up. We reviewed neuroradiology notes dictated by the neuroradiologist to obtain the angiography results. Morbidity and mortality were recorded for all patients who had complications intra- or postoperatively or who had an $\mathrm{mRS}$ score $\geq 3$ at follow-up. Patients with an $\mathrm{mRS}$ score $\geq$ 4 were considered to have suffered major morbidity.

\section{Statistical Analysis}

Statistical analysis of the difference between high-flow and low-flow outcomes and patency were completed by a professional statistician; $\mathrm{p}$ values were calculated from Fisher's exact test using RStudio (version 1.0.153).

\section{Results}

\section{Aneurysm Characteristics}

Most aneurysms were unruptured $(97 / 126,77.0 \%)$ and located within the anterior circulation (99/126, 78.6\%). The most common lesion location was the MCA (63/126, $50.0 \%$ ), of which most were at the MCA bifurcation (30, 47.6\%). Thirty-three $(26.2 \%)$ were located on the ICA, while the most common posterior circulation locations were the PICA $(14 / 27,51.9 \%)$ and the basilar artery $(10 / 27$, $37.0 \%$; Fig. 2). For more detail concerning specific aneurysm locations, see Table 1.

Aneurysm size was giant $(\geq 25 \mathrm{~mm})$ in 101 patients $(80.2 \%)$, large $(10-24 \mathrm{~mm})$ in $9(7.1 \%)$, and small $(\leq 9 \mathrm{~mm})$ in 16 patients $(12.7 \%)$. Twenty-six patients $(20.6 \%)$ had previously coiled aneurysms, and 25 patients $(19.8 \%)$ had peripherally situated aneurysms, primarily in the PICA and MCA distributions.

\section{Treatment With Revascularization}

Eighty-three patients underwent a low-flow bypass (65.9\%), and $32(25.4 \%)$ underwent a high-flow bypass. Most bypasses $(68 / 126,54.0 \%)$ were low-flow, simple STA-MCA anastomoses (Figs. 3-5). Eight patients (6.3\%) 


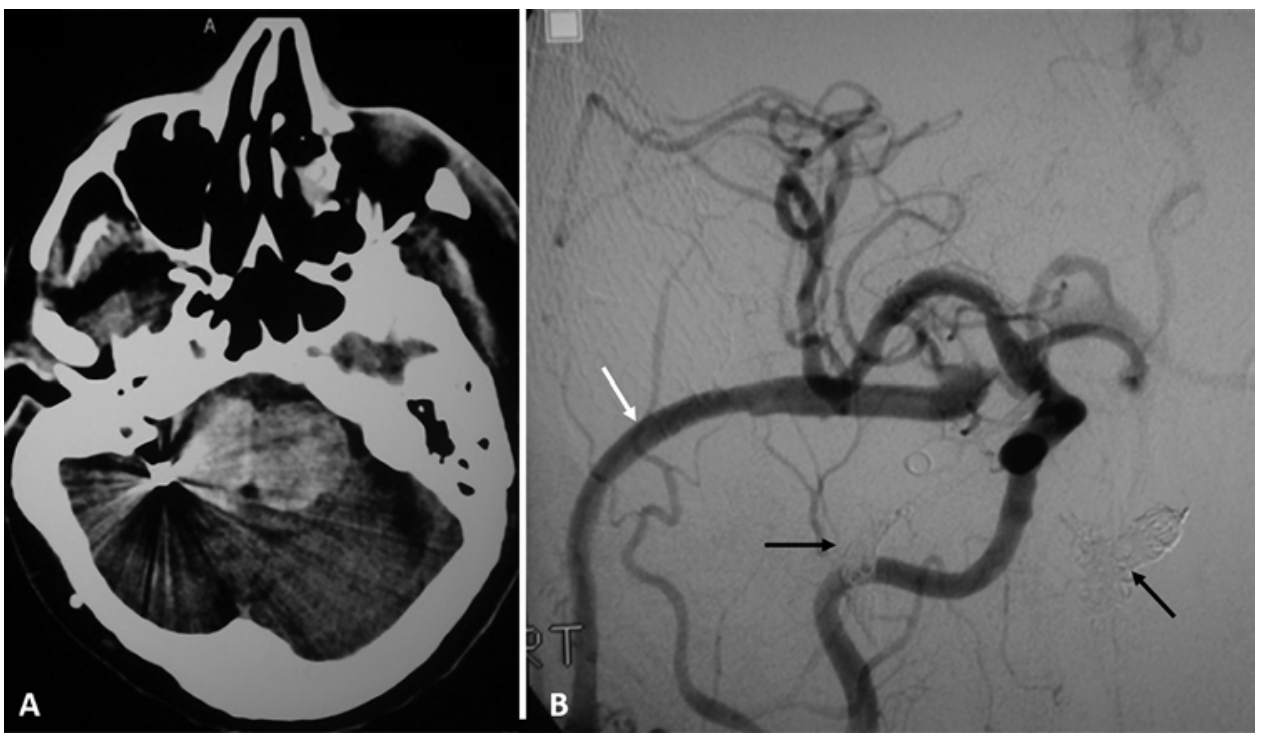

FIG. 2. Images obtained in a 62-year-old man presenting with hemorrhage from a giant dissecting basilar artery aneurysm and increasing mass effect on the brainstem. A: CT scan showing thrombosis of a giant dissecting basilar artery aneurysm and a coil in the distal vertebral artery. B: Anteroposterior injection digital subtraction (DS) angiogram of the right common carotid artery, showing filling of the anterior circulation, MCA, and ACA; patency of the saphenous vein graft (white arrow) to the PCA is also shown, with filling of the posterior circulation bilaterally. Note the coil occlusion of the distal vertebral arteries bilaterally (black arrows).

underwent occipital artery (OA)-PICA anastomosis for a PICA aneurysm, $4(3.2 \%)$ had OA-posterior cerebral artery (PCA) bypass for PCA aneurysms, and 3 (2.4\%) underwent STA-PCA grafts for complex posterior circula-

\section{TABLE 1. Characteristics of the 126 aneurysms}

\begin{tabular}{cc}
\hline Aneurysm Characteristic & No. of Aneurysms (\%) \\
\hline Rupture status & $97(77.0)$ \\
\hline Unruptured & $29(23.0)$ \\
\hline Ruptured & $16(12.7)$ \\
\hline Size, mm & $9(7.1)$ \\
\hline Small $(\leq 9)$ & $101(80.2)$ \\
\hline Large (10-24) & \\
\hline Giant ( $\geq 25)$ & $99(78.6)$ \\
\hline Location & $63(50.0)$ \\
\hline Anterior circulation & $33(26.2)$ \\
\hline MCA & $12(9.5)$ \\
\hline ICA & $11(8.7)$ \\
\hline Cavernous & $10(7.9)$ \\
\hline Paraclinoid & $2(1.6)$ \\
\hline Supraclinoid segment & $1(0.8)$ \\
\hline Anterior communicating artery & $27(21.4)$ \\
\hline Distal anterior cerebral artery & $10(7.9)$ \\
\hline Posterior circulation & $5(4.0)$ \\
\hline Basilar artery & $5(4.0)$ \\
\hline Basilar apex & $14(11.1)$ \\
\hline Arterial trunk & $3(2.4)$ \\
\hline PICA &
\end{tabular}

tion aneurysms (Fig. 6). Twenty-seven (21.4\%) high-flow grafts were lesser saphenous vein grafts anastomosed from the cervical external carotid artery (ECA) to the proximal MCA branches (Figs. 7 and 8), and $5(4.0 \%)$ were ECA-PCA bypasses. Five grafts $(4.0 \%)$ were IC-IC, while $6(4.8 \%)$ were PICA-PICA in situ. All anastomoses are summarized in Table 2 . Ninety-four $(74.6 \%)$ patients were treated with proximal occlusion and $27(21.4 \%)$ with distal occlusion of the parent artery. Trapping of the involved parent artery was only necessary in 5 cases of ruptured dissecting aneurysms, which were felt to be highly unstable lesions involving either the supraclinoid ICA (3 cases) or the $\mathrm{M}_{1}$ segment of the MCA ( 2 cases).

\section{Outcomes}

At the 12-month follow-up, 112 patients had an mRS score of 1 or $2(88.9 \%), 4$ had an mRS score of $3(3.2 \%), 6$ had an mRS score of 4 or 5 (4.8\%), and 4 patients had died (3.2\%) (Table 3). Angiographic imaging showed that 83 of 84 low-flow bypasses were patent $(98.8 \%$; 1 patient's STAMCA bypass occluded and required reoperation). Thirty (93.8\%) of 32 high-flow bypasses were patent at follow-up, meaning that low-flow bypass was associated with a slightly higher patency rate than high-flow bypass procedures; however, this difference was not statistically significant ( $p$ $=0.184$ ). All IC-IC and PICA-PICA bypasses were patent at follow-up $(11 / 11,100 \%)$. As we avoided trapping unless absolutely necessary, permanent and complete aneurysm occlusion was achieved in the 5 cases $(4.0 \%)$ of aneurysm trapping. For the remaining cases, proximal or distal occlusion diminished flow across the aneurysm segment to limit aneurysm filling, growth, and risk of rupture, while also maintaining patency of perforators arising from the aneurysm segment. 

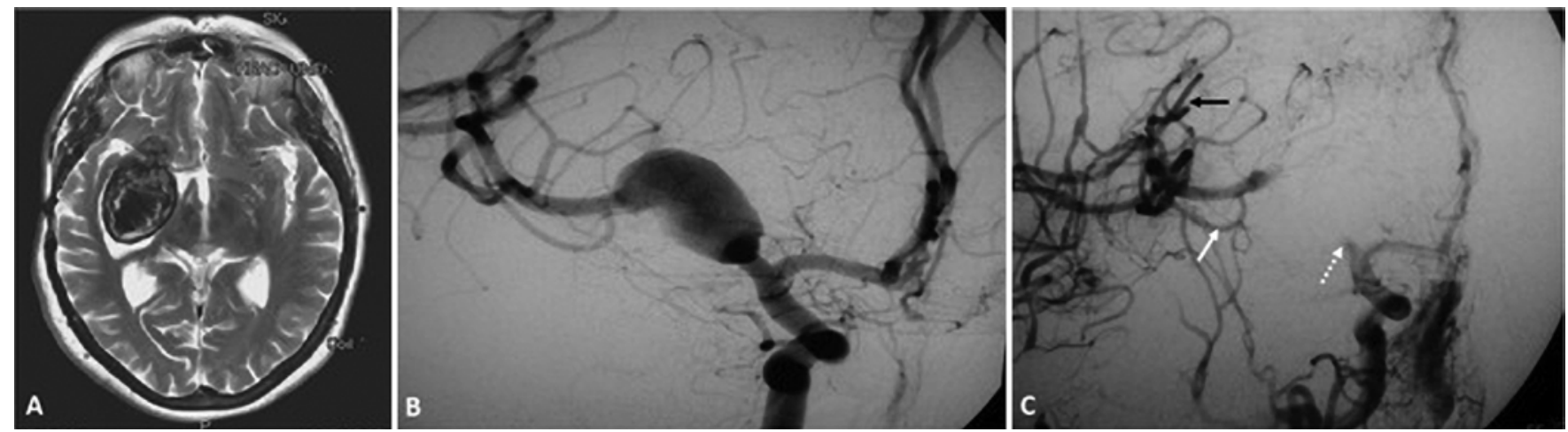

FIG. 3. A: Images obtained in a 65-year-old woman with a giant MCA aneurysm. Axial T2-weighted MR image demonstrating a giant hypointense lesion with a small amount of surrounding parenchymal hyperintensity, most compatible with a predominantly thrombosed giant aneurysm, as evidenced by lack of flow-related phase-shift artifact. B: Anteroposterior right ICA DS angiogram demonstrating uniform enlargement of the proximal half of the $\mathrm{M}_{1}$ segment, corresponding to the residual lumen of the mostly thrombosed giant aneurysm. C: Anteroposterior DS angiogram of the right common carotid artery obtained 1 day postoperatively, demonstrating occlusion of the proximal $\mathrm{M}_{1}$ segment with patency of the ACA territory. Robust flow is seen in the opercular branches of the MCA from the STA-MCA bypass (black arrow) with retrograde flow in the distal $\mathrm{M}_{1}$ segment to the level of the anterior temporal artery (white arrow). The aneurysm has been obliterated (dashed white arrow).

\section{Complications}

Major morbidity (mRS score $\geq 4$ ) occurred in 6 patients (4.8\%), and 4 patients (3.2\%) died. Of the 6 patients with major morbidity, 3 had high-flow bypass procedures, 2 had low-flow procedures, and 1 had an in situ bypass procedure. Of the 4 deaths, 2 patients had high-flow bypasses and 2 had low-flow bypasses (Table 4). Overall, of 32 patients who underwent high-flow bypass, 3 (9.4\%) had major morbidity, and $2(6.3 \%)$ died. In contrast, of 83 patients treated with low-flow bypass, 2 (2.4\%) had major morbid- ity and $2(2.4 \%)$ died. Statistical comparison between lowand high-flow bypasses found no significant differences in neurological outcome as measured by the mRS score (Table 3). IC-IC and in situ bypasses resulted in a $9.1 \%$ major morbidity rate (1 of 11 cases) and no deaths.

Serious, nonfatal complications included subacute graft occlusion resulting in cerebral infarction in 2 patients with high-flow grafts. The remaining 4 serious complications included a CSF leak associated with severe meningitis and vasospasm, acute respiratory distress syndrome as-
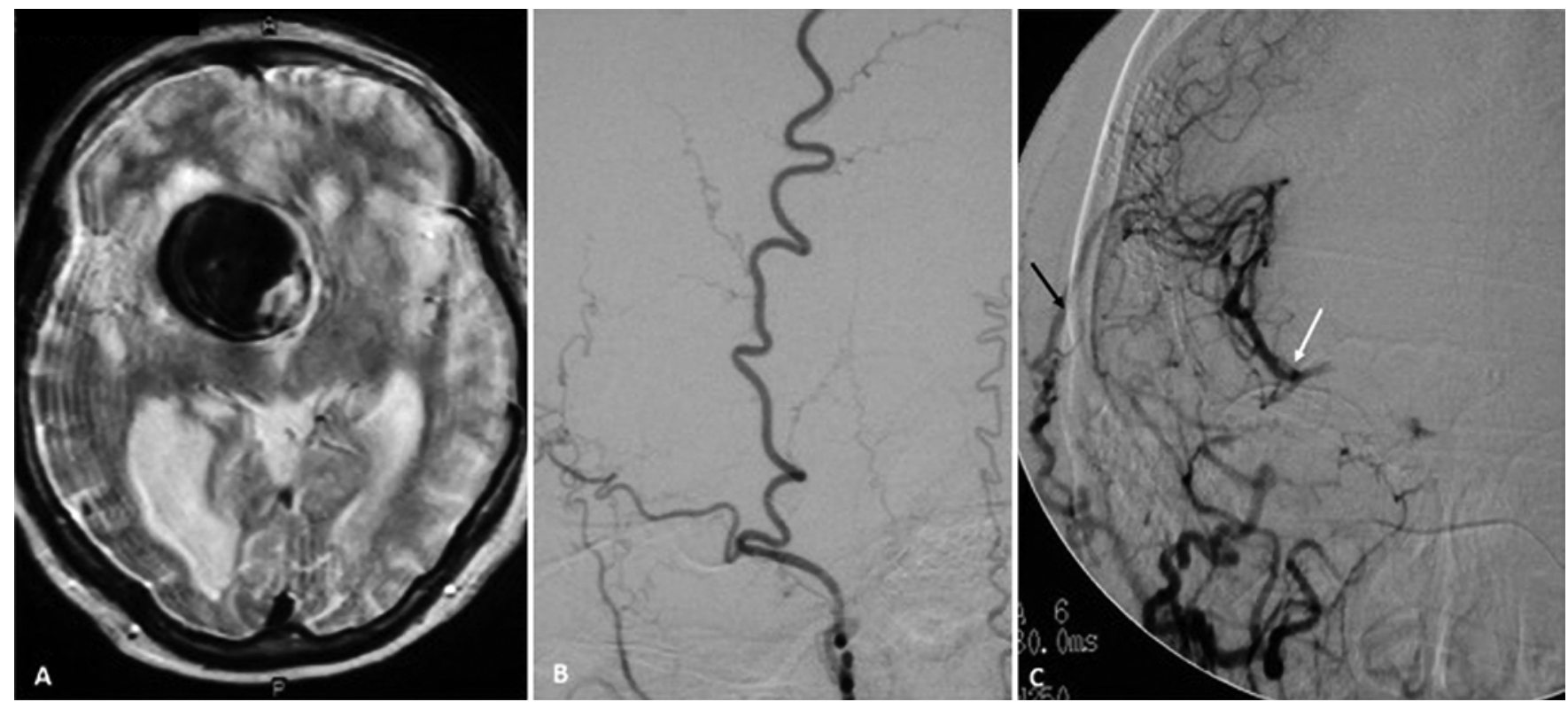

FIG. 4. Images obtained in a 63-year-old woman with a giant paraclinoid aneurysm and significant mass effect. A: Axial T2weighted MRI showing a giant aneurysm in the deep structures of the right cerebral hemisphere. B: Lateral DS angiogram showing robust flow through the STA. C: Anteroposterior angiogram of the right common carotid artery showing occlusion of the ICA. The image also shows patency of the right STA-MCA bypass (black arrow) with robust filling of the MCA territory distally and retrograde flow to the level of the distal MCA branches and $\mathrm{M}_{1}$ (white arrow). 

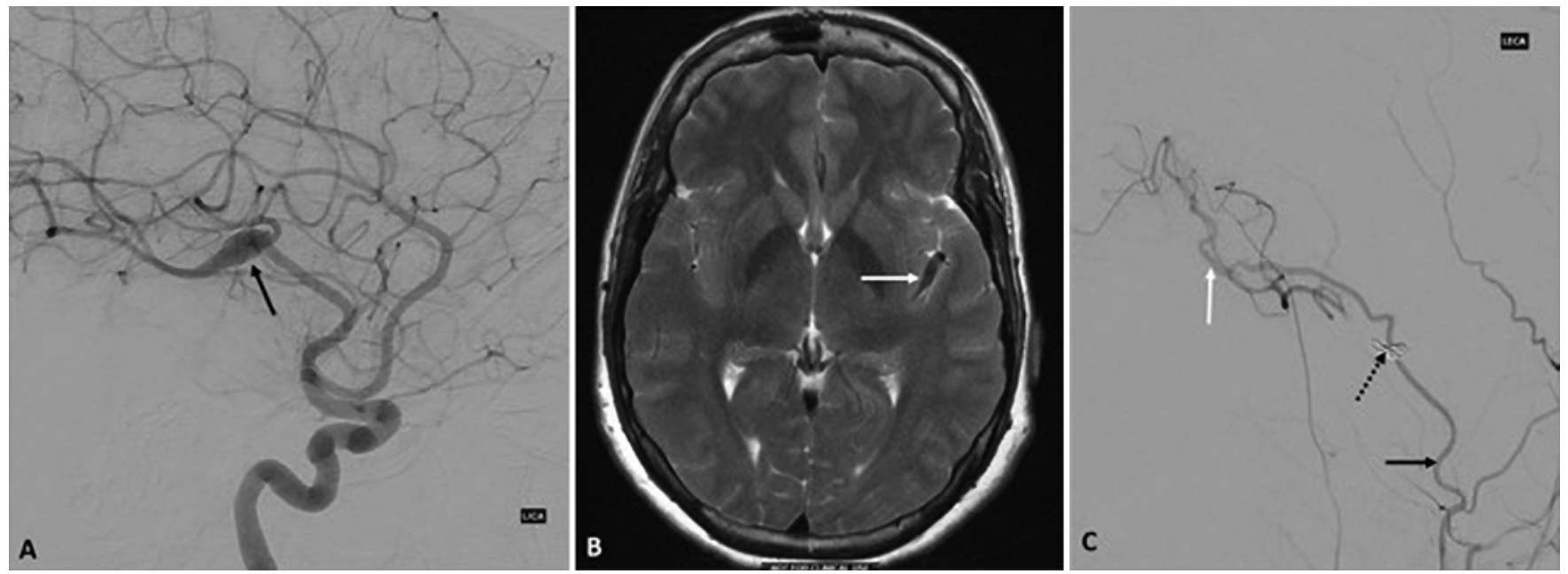

FIG. 5. Images obtained in a 27-year-old woman with CT-negative, lumbar puncture-positive SAH from a fusiform aneurysm. A: Lateral DS angiogram of the left ICA, showing fusiform enlargement of the midportion of the posterior division of the MCA (black arrow). B: Axial T2-weighted image showing elongated hypointensity residing in the left sylvian fissure compatible with fusiform aneurysm of the MCA (white arrow). C: Lateral DS angiogram of the left ECA, demonstrating patency of the STA-MCA bypass (black arrow) with excellent filling of distal MCA branches (white arrow). Note coils within the posterior division of the MCA and residual thrombosis of the branch distal to the coil. The coil is denoted by the dashed black arrow.

sociated with severe vasospasm, and severe subarachnoid hemorrhage (SAH) in 2 patients that left them with permanent significant neurological deficit. Causes of death were rebleeding of a giant dissecting basilar aneurysm (patient in Fig. 2), medical complications following wound infection precipitating sepsis and multiple organ failure, and fatal bleeding following an attempted endovascular stenting that was complicated by an anterior cerebral artery (ACA) perforation; in addition, 1 patient who presented with poor-grade (Hunt and Hess grade V) SAH never recovered consciousness.

Other complications included mild myocardial infarction in 1 patient $(0.8 \%)$, deep vein thrombosis in 5 patients $(4.0 \%)$, severe SAH in 3 patients $(2.4 \%)$, and a wound dehiscence that required revision in 1 patient $(0.8 \%)$. One patient had an epidural hematoma that required evacuation on the 3rd postoperative day $(0.8 \%)$. Another patient $(0.8 \%)$ with a giant MCA aneurysm had an STA-MCA bypass that was found to be occluded on early postoperative angiography prior to a planned endovascular $\mathrm{M}_{1}$ sacrifice and underwent reoperation to redo the bypass. There was no clinical consequence of this complication. For a comprehensive list of postoperative complications, refer to Table 4.

\section{Discussion}

In our series, even with a high proportion of large/giant and complex aneurysms, we demonstrated that cerebral revascularization with parent artery occlusion is a safe and
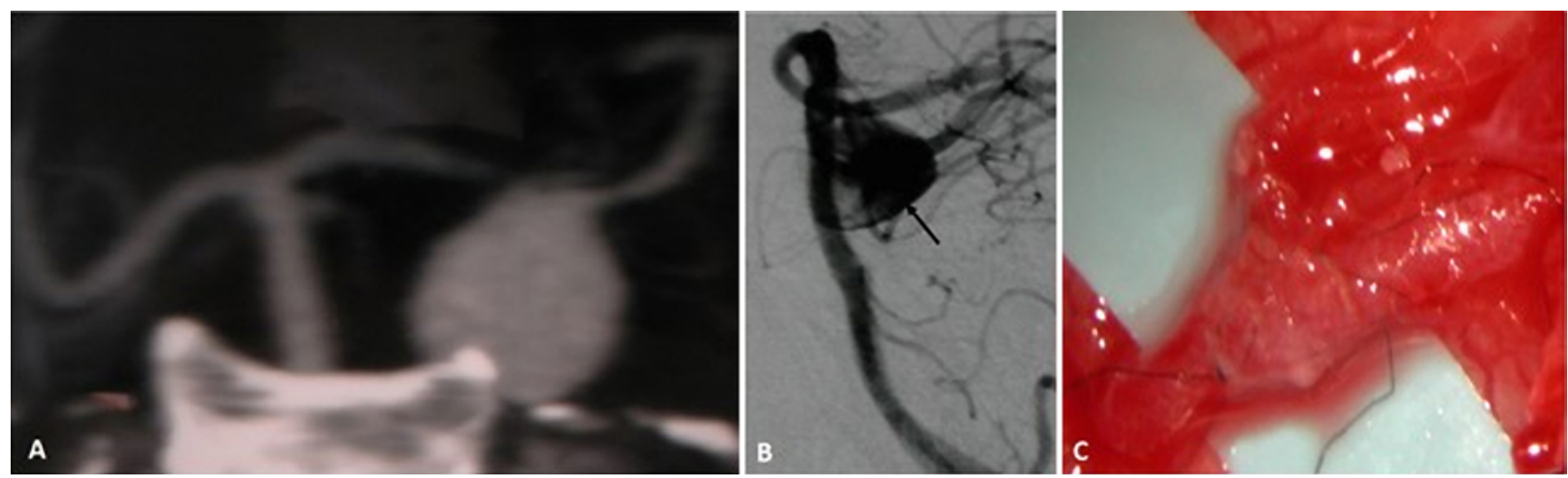

FIG. 6. Images obtained in a 23-year-old patient with a giant ruptured PCA aneurysm. A: Coronal reformatted CT angiogram showing a giant left $P_{1}-P_{2}$ junction aneurysm directed inferiorly. B: Lateral DS angiogram of a vertebral artery injection, demonstrating aneurysm overlying the left $\mathrm{P}_{1}$ segment (black arrow). $\mathrm{C}$ : Photomicrograph showing the OA-PCA bypass. Figure is available in color online only. 

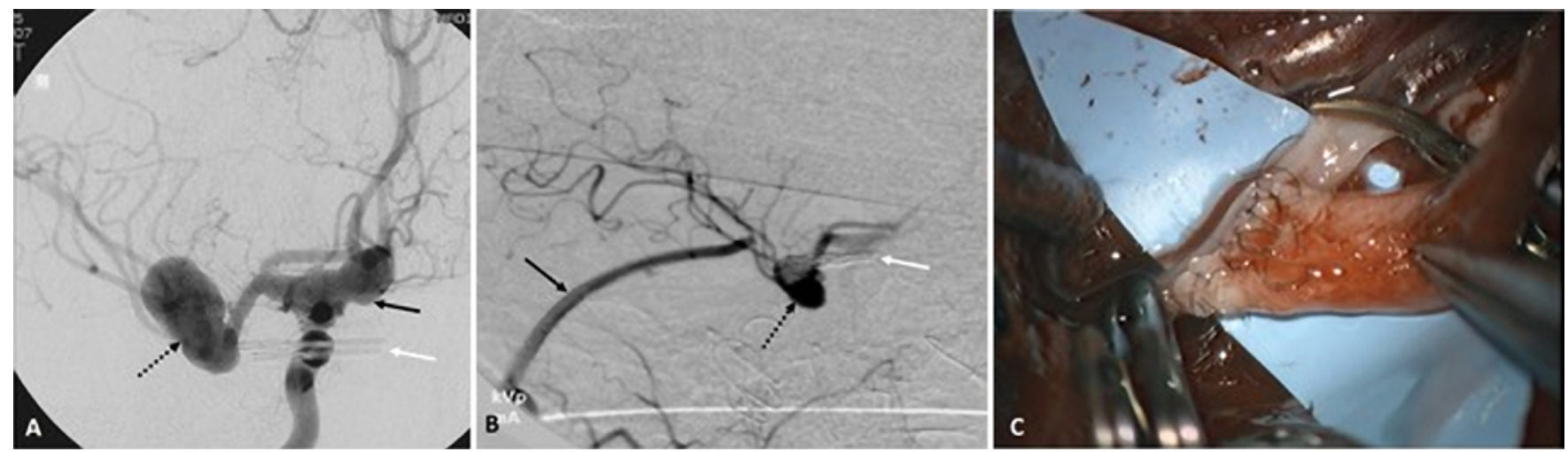

FIG. 7. Images obtained in a 50-year-old man who previously underwent clipping of a large basilar apex aneurysm and presented with fusiform enlargement of the right supraclinoid ICA and a giant right MCA aneurysm. A: Anteroposterior DS angiogram of the right ICA demonstrating a multilobulated medially projecting supraclinoid ICA aneurysm (black arrow) and a giant aneurysm (dashed black arrow) along the distal $\mathrm{M}_{1}$ segment. Note the clip on the large basilar apex aneurysm (white arrow). B: Intraoperative oblique DS angiogram of the right ECA, demonstrating the clip (white arrow) occluding the supraclinoid ICA with diminished filling of the $\mathrm{M}_{1}$ aneurysm (dashed black arrow) and brisk antegrade flow in the distal MCA branches from the ECA-MCA saphenous vein graft (black arrow). C: Intraoperative photomicrograph of saphenous vein-MCA anastomosis. Figure is available in color online only.

effective technique to address aneurysms that are not considered amenable to endovascular treatment or simple microsurgical clipping. ${ }^{11}$ Low morbidity and mortality rates for revascularization and high rates of bypass patency suggest that cerebral revascularization with parent artery occlusion can provide safe and satisfactory long-term control of the majority of complex IAs. Deep vein thrombosis and other medical complications occurring in the setting of severe SAH were the most commonly encountered com- plications, emphasizing the need to monitor for such complications in the postoperative period.

\section{Low-Flow Versus High-Flow Bypass}

There is contention in the literature concerning which bypass method has higher associated rates of neurological deficits and ischemic complications. ${ }^{16,32}$ Advantages of low-flow bypass techniques include shorter procedure
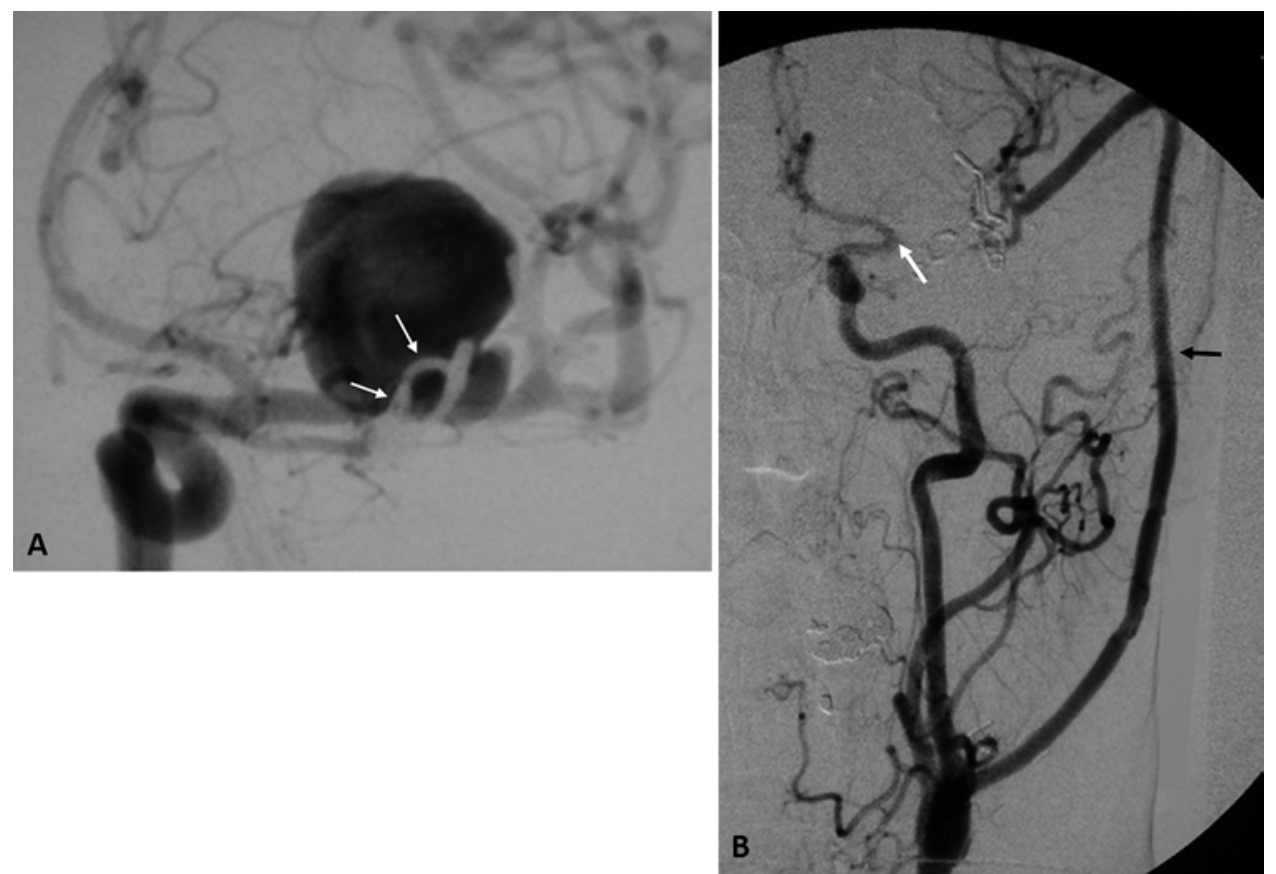

FIG. 8. Images obtained in a 42-year-old patient with a previously clipped, giant $\mathrm{M}_{1}$ aneurysm that regrew. A: Anteroposterior DS angiogram of the left ICA, showing a giant aneurysm of the mid- $\mathrm{M}_{1}$ segment. Note the fenestrated aneurysm clip along its base (white arrows). B: Anteroposterior DS angiogram of left common carotid artery, showing the ECA-MCA saphenous vein graft (black arrow) with excellent filling of MCA branches and occlusion (white arrow) of the $\mathrm{M}_{1}$ segment and the aneurysm. 
TABLE 2. Anastomosis locations

\begin{tabular}{cc}
\hline \multicolumn{1}{c}{ Bypass } & No. of Aneurysms $(\%)$ \\
\hline STA-MCA, low flow & $68(54.0)$ \\
\hline STA-PCA, low flow & $3(2.4)$ \\
\hline OA-PICA, low flow & $8(6.3)$ \\
\hline OA-PCA, low flow & $4(3.2)$ \\
\hline ECA-MCA, high flow & $27(21.4)$ \\
\hline ECA-PCA, high flow & $5(4.0)$ \\
\hline IC-IC* & $5(4.0)$ \\
\hline PICA-PICA in situ* & $6(4.8)$ \\
\hline
\end{tabular}

${ }^{*}$ Neither IC-IC nor PICA-PICA bypasses have been classified in the literature as high-or low-flow, and they were therefore excluded from this comparison.

times and fewer opportunities for intraoperative complications given the need for fewer anastomoses. In our series, the majority of patients were treated using low-flow bypass with excellent clinical outcomes; this contrasts with other studies ${ }^{29,34}$ which have favored high-flow bypass in more than $75 \%$ of cases. We observed no statistically significant differences in postoperative ischemic complications between high- and low-flow bypass, suggesting that low-flow bypass is an important and potentially underutilized option in selected cases in which adequate blood flow can be achieved using a lower-flow bypass technique.

The choice of surgical approach and bypass type can often be made based on the particular anatomy associated with the aneurysm and the adequacy of native collateral supply. When ICA sacrifice is contemplated, BTO and subsequent categorization as described above can be utilized to aid in deciding between low- and high-flow bypass. Our excellent clinical outcomes and, in particular, the lack of ischemic complications following parent artery occlusion in a series in which the majority of the bypasses were low flow, supports its wider utilization. Furthermore, because this is the first series to describe the use of a majority of low-flow bypasses in the management of IAs, the present series provides a benchmark for future comparison between bypass types.

\section{Aneurysm Trapping}

Although prior studies have generally utilized aneurysm trapping, we have found that either isolated proximal or distal parent artery occlusion performed either surgically or endovascularly has generally been adequate to achieve aneurysm occlusion. Trapping of the involved segment was only deemed necessary in select cases of ruptured, dissecting aneurysms involving the supraclinoid ICA or $M_{1}$ segments because of the highly dynamic and unstable nature of these lesions. In our experience, revascularization and parent artery occlusion has been safer than attempted direct clip reconstruction of such acutely ruptured, dissecting aneurysms, which have a great tendency to rebleed during surgical exploration and attempted direct reconstruction. Our low rate of rebleeding following proximal or distal occlusion alone suggests that avoiding aneurysm trapping is a viable strategy for aneurysm treatment, effectively limiting the risk of aneurysm rebleeding
TABLE 3. Neurological outcome at 12 months based on high flow versus low flow

\begin{tabular}{cccc}
\hline & \multicolumn{2}{c}{ No. of Patients (\%) } & \\
\cline { 2 - 3 } mRS Score $^{*}$ & Low Flow & High Flow & p Value \\
\hline 1 or 2 & $75(90.4)$ & $27(84.4)$ & 0.74 \\
\hline 3 & $4(4.8)$ & $0(0)$ & 0.57 \\
\hline 4 or 5 & $2(2.4)$ & $3(9.4)$ & 0.13 \\
\hline 6 & $2(2.4)$ & $2(6.3)$ & 0.31 \\
\hline Total & 83 & 32 & \\
\hline
\end{tabular}

* An mRS score of 1 or 2 is considered a good outcome, an mRS score $\geq 3$ is considered morbidity, and an mRS score $\geq 4$ is considered major morbidity. † Low-flow versus high-flow bypass. Calculated as Fisher exact test statistic between patient categories. Significance was based on $p<0.05$.

while also minimizing the risk of ischemic injury from loss of local perforators that may also be trapped between the clips. Future studies from other centers comparing the long-term efficacy of such isolated proximal or distal occlusion compared with trapping will be valuable in providing additional data on this issue.

\section{Comparison to Previous Studies of Cerebral Revascularization}

In our experience, achieving a successful outcome in these complex cases depends on a combination of factors, including an extensive preoperative evaluation of cerebral blood flow dynamics, an assessment of the surgical anatomy related to the aneurysm with its associated branches and perforators, an understanding of the status of cerebrovascular reserve, and the surgeon's expertise and facility with the revascularization techniques being performed. ${ }^{3,28}$ The current study spans a long period of time during which the development of newer endovascular therapies such as stent reconstruction have altered patient management strategies, but understanding the outcomes and risks associated with bypass remains important in weighing its use for patients with IAs., ${ }^{9,35}$

Worldwide, acceptable bypass morbidity ranges between $6 \%$ and $16 \%$, with subacute graft occlusion accounting for $0 \%-4 \%$ of all complications, while mortality varies from $2 \%$ to $12 \%{ }^{7,14,25,34}$ In the case of ruptured aneurysms, bypass techniques were used in $7 \%$ of surveyed cases, with a mortality of $21 \%{ }^{3}$ Similar aneurysm characteristics and clinical presentations to the current study have been described by Kato et al., who treated 139 large and giant aneurysms using trapping, multiple clips, or aneurysmectomy with bypass; however, their study reported $24.5 \%$ morbidity and $7.9 \%$ mortality. ${ }^{12}$ This high rate of complications was unrelated to whether the aneurysm had ruptured and shows that the incidence of complication may vary significantly between centers, limiting the possible extrapolation of results from single-center studies. In Lawton and colleagues' analysis of Dr. Spetzler's experience with bypass for complex aneurysms, the complication rate was $10 \%$ in a series of 63 complex aneurysms in 61 patients. $^{13}$ Of all the complications, $7 \%$ were directly related to the bypass procedure and 3\% to nonneurological 
TABLE 4. Comprehensive list of perioperative and postoperative complications

\begin{tabular}{|c|c|c|c|c|c|c|c|}
\hline $\begin{array}{l}\text { Patient } \\
\text { No. }\end{array}$ & $\begin{array}{l}\text { Sex } \\
\text { (yrs), } \\
\text { Age }\end{array}$ & $\begin{array}{l}\text { Location of } \\
\text { Aneurysm }\end{array}$ & Rupture & Size & $\begin{array}{l}\text { Type of Bypass } \\
\text { (flow rate) }\end{array}$ & Brief Description of Complication & Outcome \\
\hline 1 & $71, \mathrm{M}$ & $\begin{array}{l}\text { Dissecting, basi- } \\
\quad \text { lar artery }\end{array}$ & Yes & Giant & ECA-PCA (high flow) & Rebleed & Death \\
\hline 2 & $66, M$ & Peripheral PICA & Yes & Giant & OA-PICA (low flow) & $\begin{array}{l}\text { Infection, sepsis, multisystem organ } \\
\text { failure }\end{array}$ & Death \\
\hline 3 & $39, \mathrm{M}$ & Dissecting $\mathrm{M}_{1}$ & Yes & Giant & STA-MCA (low flow) & $\begin{array}{l}\text { ACA perforation during endovascular } \\
\text { attempt to occlude vessel }\end{array}$ & Death \\
\hline 4 & $58, \mathrm{~F}$ & MCA & Yes & Giant & ECA-M ${ }_{2}$ (high flow) & $\begin{array}{l}\text { Grade V SAH, never regained con- } \\
\text { sciousness }\end{array}$ & Death \\
\hline 5 & $64, \mathrm{M}$ & MCA & No & Giant & $\begin{array}{l}\text { ECA-M }, 2 \text { grafts, } 1 \text { to } \\
\text { anterior division, } 1 \\
\text { to posterior division } \\
\text { (high flow) }\end{array}$ & $\begin{array}{l}\text { Subacute graft occlusion resulting in } \\
\text { disabling stroke }\end{array}$ & $\begin{array}{l}\text { Hemiplegia, cognitively good, } \\
\text { but requiring assistance for } \\
\text { daily living, mRS score } 4\end{array}$ \\
\hline 6 & $72, \mathrm{M}$ & Basilar trunk & Yes & Giant & ECA-PCA (high flow) & $\begin{array}{l}\text { Subacute graft occlusion resulting in } \\
\text { disabling stroke }\end{array}$ & $\begin{array}{l}\text { Severe disability, skilled nursing } \\
\text { facility, mRS score } 5\end{array}$ \\
\hline 7 & $61, \mathrm{~F}$ & Paraclinoid & Yes & Giant & STA-MCA (low flow) & $\begin{array}{l}\text { Severe SAH, permanent severe defi- } \\
\text { cit, dependent condition in skilled } \\
\text { nursing facility }\end{array}$ & Nursing home, mRS score 5 \\
\hline 8 & $68, M$ & MCA & No & Giant & STA-MCA (low flow) & $\begin{array}{l}\text { Bypass occluded on early follow-up } \\
\text { angiogram necessitating reop w/ } \\
\text { redo bypass prior to vessel sacrifice }\end{array}$ & $\begin{array}{l}\text { No clinical consequence, full } \\
\text { recovery }\end{array}$ \\
\hline 9 & $63, \mathrm{M}$ & Peripheral PICA & Yes & Giant & PICA-PICA (in situ) & $\begin{array}{l}\text { CSF leak, severe meningitis, vaso- } \\
\text { spasm }\end{array}$ & $\begin{array}{l}\text { Prolonged rehab stay, indepen- } \\
\text { dent, hemiparesis, diplopia } \\
\text { from 6th nerve palsy, mRS } \\
\text { score } 4\end{array}$ \\
\hline 10 & $49, \mathrm{~F}$ & Paraclinoid & Yes & Giant & STA-MCA (low flow) & ARDS, vasospasm & $\begin{array}{r}\text { Prolonged rehab, ultimate mod- } \\
\text { erate disability, mRS score } 4\end{array}$ \\
\hline 11 & $73, \mathrm{~F}$ & Supraclinoid ICA & Yes & Giant & ECA-M 2 (high flow) & $\begin{array}{l}\text { Severe SAH, permanent severe defi- } \\
\text { cit, dependent condition in skilled } \\
\text { nursing facility }\end{array}$ & $\begin{array}{l}\text { Dependent, nursing home, mRS } \\
\text { score } 5\end{array}$ \\
\hline 12 & $55, \mathrm{M}$ & Basilar & No & Giant & ECA-PCA (high flow) & $\begin{array}{l}\text { DVT, treated w/ anticoagulation \& IVC } \\
\text { filter }\end{array}$ & Normal \\
\hline 13 & $39, \mathrm{~F}$ & MCA & No & Giant & STA-MCA (low flow) & $\begin{array}{l}\text { DVT, treated w/ anticoagulation \& IVC } \\
\text { filter, full recovery }\end{array}$ & Normal \\
\hline 14 & $42, \mathrm{M}$ & Supraclinoid ICA & Yes & Giant & STA-MCA (low flow) & DVT, vasospasm & mRS score 3 \\
\hline 15 & $59, \mathrm{~F}$ & Cavernous ICA & No & Giant & STA-MCA (low flow) & DVT & Normal \\
\hline 16 & $44, \mathrm{M}$ & Paraclinoid & Yes & Giant & STA-MCA (low flow) & DVT, severe vasospasm & mRS score 3 \\
\hline 17 & $65, \mathrm{~F}$ & Paraclinoid & No & Giant & STA-MCA (low flow) & $\begin{array}{l}\text { Epidural hematoma developed POD } 3 \\
\text { probably related to anticoagulation, } \\
\text { required surgical evacuation }\end{array}$ & Normal \\
\hline 18 & $68, \mathrm{M}$ & Supraclinoid ICA & Yes & Giant & STA-MCA (low flow) & Mild myocardial infarction & Normal \\
\hline 19 & $45, \mathrm{~F}$ & Paraclinoid & No & Giant & $\begin{array}{l}\text { STA-MCA, } 2 \text { bypass- } \\
\text { es using both STA } \\
\text { divisions (double } \\
\text { barrel; low flow) }\end{array}$ & $\begin{array}{l}\text { Wound dehiscence requiring revision } \\
\text { surgery }\end{array}$ & Normal \\
\hline 20 & $44, \mathrm{~F}$ & Supraclinoid ICA & Yes & Large & STA-MCA (low flow) & Severe $\mathrm{SAH}$, prolonged vasospasm & mRS score 3 \\
\hline 21 & $70, \mathrm{M}$ & MCA & Yes & Giant & STA-MCA (low flow) & Severe SAH, prolonged vasospasm & mRS score 3 \\
\hline
\end{tabular}

ARDS = acute respiratory distress syndrome; DVT = deep vein thrombosis; IVC = inferior vena cava; $P O D$ = postoperative day; rehab = rehabilitation. 
causes. ${ }^{13,22}$ The current study's low rates of both morbidity and mortality demonstrate that bypass remains a potential alternative to endovascular therapy and is a particularly useful adjunct to limit the risk of distal ischemic injury when parent artery occlusion is contemplated. Low-flow STA-MCA bypass preserved adequate flow in many cases in our series, including in selected cases of ICA occlusion, precluding the need for high-flow anastomosis. We suggest that such low-flow bypass may represent a favorable option given its simplicity and the excellent clinical outcomes that were achieved using lower-flow bypass in our series. It should be noted that, despite our reasonable results, we were challenged in controlling ischemic and hemorrhagic complications at the time of parent artery occlusion of giant dissecting basilar aneurysms, a subset of lesions that remains a challenging and ongoing management problem for neurovascular surgeons. ${ }^{8}$

\section{High-Volume Centers and Complication Rates}

Lower complication rates at high-volume centers have been demonstrated in both endovascular ${ }^{6}$ and open microsurgical ${ }^{5}$ aneurysm care, suggesting that complex aneurysms may be best addressed at highly specialized centers. ${ }^{6}$ Nevertheless, there has been a recent trend toward aneurysm treatment at low-volume hospitals ${ }^{6}$ as well as the appearance of centers offering exclusively or almost exclusively endovascular treatment options. ${ }^{30}$ It is likely that these developments will further erode proficiency with open microsurgery for IAs, particularly the more complicated cerebral revascularization techniques described in this report. This suggests that as the expansion of endovascular therapy further limits the role of open microsurgery for IAs, the treatment of those aneurysms that are not amenable to simple endovascular therapy should be undertaken as much as possible by specialized and experienced teams that can offer the full spectrum of treatment options and that have demonstrated lower rates of complications..$^{11,13,24}$

\section{IC-IC and In Situ Bypass}

In this series, we used on occasion both IC-IC bypasses, which avoid the need to bypass from an extracranial donor artery, and in situ options, which avoid the need for a donor vessel completely. A previous report by Sanai et al. illustrated that IC-IC bypasses have patency and complication rates that are similar to those of extracranial-IC bypasses, ${ }^{26}$ while Abla et al. have argued that PICA aneurysms respond best to PICA-PICA anastomosis. ${ }^{1}$ In this series, we performed 11 IC-IC and in situ bypasses with only one major complication, corroborating basic safety and efficacy, but larger studies are needed to demonstrate the complication rates and relative safety of IC-IC and in situ bypasses, which may put at risk normal vascular territories that are used as the "donor" vessels in such cases.

\section{Limitations}

This study has a number of important limitations. Our statistical analysis was likely limited by insufficient power for comparison of patency between low- and high-flow bypasses. In addition, our conclusions were limited based on the fact that we drew from a single surgeon's experience, which may mean they are not representative of generalized surgical results. The study also spans an 18 -year period, so the indications for surgery and techniques of both bypass and competing surgical options were not consistent across all patients. Though we presented follow-up information on morbidity and mortality, we did not gather data about patients with similar presentations who underwent alternative treatment options, and, therefore, we could not provide a direct comparison of outcomes.

\section{Conclusions}

Revascularization is a critical tool in the management of select patients with complex intracranial aneurysms. Aneurysm treatment centers capable of offering various bypass techniques are essential for the management of such challenging lesions, and BTO provides a classification method for low- versus high-flow bypass in selected cases. Our comparisons between high-flow and low-flow bypasses showed high rates of patency and low complication rates for low-flow bypass, demonstrating that lowflow bypass, given its simplicity, should be considered in selected patients as described above. We also found that either proximal or distal parent artery occlusion alone provides excellent long-term aneurysm control, potentially avoiding the use of the more traditional option of trapping the involved segment, which may carry an increased risk of local perforator injury. Since this is a single-center experience, we recommend further studies to compare low- versus high-flow bypasses. Despite the trend toward management of IAs in smaller centers, including centers that offer only endovascular therapy, we suggest that more complex lesions such as those described in this report are best managed in highly specialized centers that maintain the full spectrum of management options, including both endovascular and open microsurgical techniques.

\section{Acknowledgments}

We received a grant from the United Hospital Foundation in support of this work.

We would like to acknowledge Jodi Lowary, CNRN, for her assistance with the management of many of these complex patients. We also acknowledge the copy editing support of Superior Medical Experts.

\section{References}

1. Abla AA, McDougall CM, Breshears JD, Lawton MT: Intracranial-to-intracranial bypass for posterior inferior cerebellar artery aneurysms: options, technical challenges, and results in 35 patients. J Neurosurg 124:1275-1286, 2016

2. Aguilar-Pérez M, Kurre W, Fischer S, Bäzner H, Henkes H: Coil occlusion of wide-neck bifurcation aneurysms assisted by a novel intra- to extra-aneurysmatic neck-bridging device (pCONus): initial experience. AJNR Am J Neuroradiol 35:965-971, 2014

3. Amin-Hanjani S, Butler WE, Ogilvy CS, Carter BS, Barker FG II: Extracranial-intracranial bypass in the treatment of occlusive cerebrovascular disease and intracranial aneurysms in the United States between 1992 and 2001: a populationbased study. J Neurosurg 103:794-804, 2005

4. Balaz P, Rokosny S, Klein D, Adamec M: Aneurysmorrhaphy is an easy technique for arteriovenous fistula salvage. J Vasc Access 9:81-84, 2008 
5. Barker FG II, Amin-Hanjani S, Butler WE, Ogilvy CS, Carter BS: In-hospital mortality and morbidity after surgical treatment of unruptured intracranial aneurysms in the United States, 1996-2000: the effect of hospital and surgeon volume. Neurosurgery 52:995-1009, 2003

6. Brinjikji W, Lanzino G, Kallmes DF, Cloft HJ: Cerebral aneurysm treatment is beginning to shift to low volume centers. J Neurointerv Surg 6:349-352, 2014

7. Drake CG, Peerless SJ, Ferguson GG: Hunterian proximal arterial occlusion for giant aneurysms of the carotid circulation. J Neurosurg 81:656-665, 1994

8. Ewald C, Kühne D, Hassler W: Giant basilar artery aneurysms encorporating the posterior cerebral artery: bypass surgery and coil occlusion-two case reports. Neurol Med Chir (Tokyo) 38 Suppl:83-85, 1998

9. Fraser JF, Stieg PE: Surgical bypass for intracranial aneurysms: navigating around a changing paradigm. World Neurosurg 75:414-417, 2011

10. Gewirtz RJ, Awad IA: Giant aneurysms of the anterior circle of Willis: management outcome of open microsurgical treatment. Surg Neurol 45:409-421, 1996

11. Kalani MYS, Rangel-Castilla L, Ramey W, Nakaji P, Albuquerque FC, McDougall CG, et al: Indications and results of direct cerebral revascularization in the modern era. World Neurosurg 83:345-350, 2015

12. Kato Y, Sano H, Imizu S, Yoneda M, Viral M, Nagata J, et al: Surgical strategies for treatment of giant or large intracranial aneurysms: our experience with 139 cases. Minim Invasive Neurosurg 46:339-343, 2003

13. Lawton MT, Hamilton MG, Morcos JJ, Spetzler RF: Revascularization and aneurysm surgery: current techniques, indications, and outcome. Neurosurgery 38:83-94, 1996

14. Lawton MT, Spetzler RF: Surgical management of giant intracranial aneurysms: experience with 171 patients. Clin Neurosurg 42:245-266, 1995

15. Mack WJ, Ducruet AF, Angevine PD, Komotar RJ, Shrebnick DB, Edwards NM, et al: Deep hypothermic circulatory arrest for complex cerebral aneurysms: lessons learned. Neurosurgery 62 (6 Suppl 3):1311-1323, 2008

16. Matsukawa H, Miyata S, Tsuboi T, Noda K, Ota N, Takahashi $\mathrm{O}$, et al: Rationale for graft selection in patients with complex internal carotid artery aneurysms treated with extracranial to intracranial high-flow bypass and therapeutic internal carotid artery occlusion. J Neurosurg 128:1753-1761, 2018

17. McDougall CG, Johnston SC, Gholkar A, Barnwell SL, Vazquez Suarez JC, Massó Romero J, et al: Bioactive versus bare platinum coils in the treatment of intracranial aneurysms: the MAPS (Matrix and Platinum Science) trial. AJNR Am J Neuroradiol 35:935-942, 2014

18. Nussbaum ES: Surgical distal outflow occlusion for the treatment of complex intracranial aneurysms: experience with 18 cases. Neurosurgery 11 (Suppl 2):8-16, 2015

19. Nussbaum ES, Mocco J: Cerebral Revascularization: Microsurgical and Endovascular Techniques. Stuttgart: Thieme Medical Publishers, 2011

20. Nussbaum L, Defillo A, Zelensky A, Nussbaum ES: A short segment intracranial-intracranial jump graft bypass followed by proximal arterial occlusion for a distal MCA aneurysm. Surg Neurol Int 2:98, 2011

21. Ohno K, Arai T, Isotani E, Nariai T, Hirakawa K: Ischaemic complication following obliteration of unruptured cerebral aneurysms with atherosclerotic or calcified neck. Acta Neurochir (Wien) 141:699-706, 1999

22. O'Shaughnessy BA, Salehi SA, Mindea SA, Batjer HH: Selective cerebral revascularization as an adjunct in the treatment of giant anterior circulation aneurysms. Neurosurg Focus 14(3):e4, 2003
23. Pancucci G, Potts MB, Rodríguez-Hernández A, Andrade H, Guo L, Lawton MT: Rescue bypass for revascularization after ischemic complications in the treatment of giant or complex intracranial aneurysms. World Neurosurg 83:912-920, 2015

24. Quiñones-Hinojosa A, Du R, Lawton MT: Revascularization with saphenous vein bypasses for complex intracranial aneurysms. Skull Base 15:119-132, 2005

25. Regli L, Piepgras DG, Hansen KK: Late patency of long saphenous vein bypass grafts to the anterior and posterior cerebral circulation. J Neurosurg 83:806-811, 1995

26. Sanai N, Zador Z, Lawton MT: Bypass surgery for complex brain aneurysms: an assessment of intracranial-intracranial bypass. Neurosurgery 65:670-683, 2009

27. Seibert B, Tummala RP, Chow R, Faridar A, Mousavi SA, Divani AA: Intracranial aneurysms: review of current treatment options and outcomes. Front Neurol 2:45, 2011

28. Sekhar LN, Kalavakonda C: Cerebral revascularization for aneurysms and tumors. Neurosurgery 50:321-331, 2002

29. Sekhar LN, Natarajan SK, Ellenbogen RG, Ghodke B: Cerebral revascularization for ischemia, aneurysms, and cranial base tumors. Neurosurgery 62 (6 Suppl 3):1373-1410, 2008

30. Siddiq F, Adil MM, Kainth D, Moen S, Qureshi AI: The emergence of endovascular treatment-only centers for treatment of intracranial aneurysms in the United States. J Stroke Cerebrovasc Dis 22:e504-e510, 2013

31. Straus DC, Brito da Silva H, McGrath L, Levitt MR, Kim LJ, Ghodke BV, et al: Cerebral revascularization for aneurysms in the flow-diverter era. Neurosurgery 80:759-768, 2017

32. Surdell DL, Hage ZA, Eddleman CS, Gupta DK, Bendok BR, Batjer HH: Revascularization for complex intracranial aneurysms. Neurosurg Focus 24(2):E21, 2008

33. Turk AS III, Martin RH, Fiorella D, Mocco J, Siddiqui A, Bonafe A: Flow diversion versus traditional endovascular coiling therapy: design of the prospective LARGE aneurysm randomized trial. AJNR Am J Neuroradiol 35:1341-1345, 2014

34. Xu BN, Sun ZH, Wu C, Jiang JL, Zhou DB, Yu XG, et al: Revascularization for complex cerebral aneurysms. Can J Neurol Sci 38:712-718, 2011

35. Zhu W, Tian YL, Zhou LF, Song DL, Xu B, Mao Y: Treatment strategies for complex internal carotid artery (ICA) aneurysms: direct ICA sacrifice or combined with extracranialto-intracranial bypass. World Neurosurg 75:476-484, 2011

\section{Disclosures}

Kevin Kallmes works for and holds equity in Superior Medical Experts.

\section{Author Contributions}

Conception and design: ES Nussbaum, Lassig, Goddard, Madison, LA Nussbaum. Acquisition of data: all authors. Analysis and interpretation of data: all authors. Drafting the article: all authors. Critically revising the article: all authors. Reviewed submitted version of manuscript: all authors. Approved the final version of the manuscript on behalf of all authors: ES Nussbaum. Administrative/technical/material support: ES Nussbaum. Study supervision: ES Nussbaum.

\section{Correspondence}

Eric S. Nussbaum: National Brain Aneurysm Center, United Hospital, St.Paul, MN. lnussbaum@comcast.net. 